\title{
Preserving Catalytic Activity and Enhancing Biochemical Stability of the Therapeutic Enzyme Asparaginase by Biocompatible Multilayered Polyelectrolyte Microcapsules
}

\author{
Christos S. Karamitros, ${ }_{\dagger}^{\dagger}$ Alexey M. Yashchenok, ${ }^{\ddagger}$ Helmuth Möhwald, ${ }^{\ddagger}$ Andre G. Skirtach, ${ }^{\ddagger}$, \\ and Manfred Konrad* ${ }^{*} \dagger$ \\ ${ }^{\dagger}$ Enzyme Biochemistry Group, Max-Planck Institute for Biophysical Chemistry, Göttingen, D-37077, Germany \\ ${ }^{\ddagger}$ Department of Interfaces, Max-Planck Institute of Colloids and Interfaces, Potsdam, D-14424, Germany \\ ${ }^{\S}$ Department of Molecular Biotechnology, Centre for Nano-Biophotonics, Ghent University, Ghent, B-9000, Belgium
}

\section{Supporting Information}

ABSTRACT: The present study focuses on the formation of microcapsules containing catalytically active L-asparaginase (LASNase), a protein drug of high value in antileukemic therapy. We make use of the layer-by-layer ( $\mathrm{LbL}$ ) technique to coat protein-loaded calcium carbonate $\left(\mathrm{CaCO}_{3}\right)$ particles with two

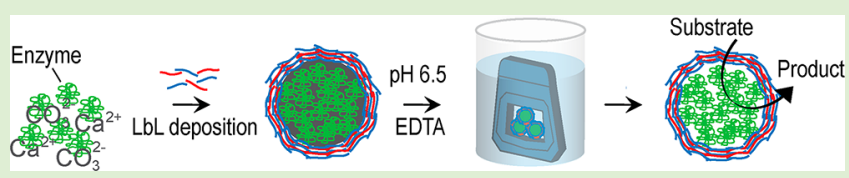
or three poly dextran/poly-L-arginine-based bilayers. To achieve high loading efficiency, the $\mathrm{CaCO}_{3}$ template was generated by coprecipitation with the enzyme. After assembly of the polymer shell, the $\mathrm{CaCO}_{3}$ core material was dissolved under mild conditions by dialysis against $20 \mathrm{mM}$ EDTA. Biochemical stability of the encapsulated L-asparaginase was analyzed by treating the capsules with the proteases trypsin and thrombin, which are known to degrade and inactivate the enzyme during leukemia treatment, allowing us to test for resistance against proteolysis by physiologically relevant proteases through measurement of residual L-asparaginase activities. In addition, the thermal stability, the stability at the physiological temperature, and the longterm storage stability of the encapsulated enzyme were investigated. We show that encapsulation of L-asparaginase remarkably improves both proteolytic resistance and thermal inactivation at $37^{\circ} \mathrm{C}$, which could considerably prolong the enzyme's in vivo half-life during application in acute lymphoblastic leukemia (ALL). Importantly, the use of low EDTA concentrations for the dissolution of $\mathrm{CaCO}_{3}$ by dialysis could be a general approach in cases where the activity of sensitive biomacromolecules is inhibited, or even irreversibly damaged, when standard protocols for fabrication of such LbL microcapsules are used. Encapsulated and free enzyme showed similar efficacies in driving leukemic cells to apoptosis.

\section{INTRODUCTION}

The catabolic enzyme L-asparaginase (L-asparagine amidohydrolase, EC 3.5.1.1; L-ASNase) catalyzes the hydrolysis of the amino acid asparagine to aspartic acid and ammonia. It is present in organisms ranging from bacteria to mammals, though its activity rarely is essential for cell viability. In humans, beyond its metabolic role, L-ASNase serves as a therapeutic enzyme that is used in combination with other drugs, such as vincristine and prednisone for the treatment primarily of acute lymphoblastic leukemia (ALL) and secondarily of non-Hodgkin lymphoma. ${ }^{1}$ ALL is the most common childhood blood cancer, with a long-term survival rate around $80 \%{ }^{2,3}$ The antiproliferating properties of L-ASNase were first identified and characterized in human clinical trials in the 1970s. ${ }^{4-7}$ Since then, this enzyme has become a milestone in the treatment of ALL. The principle of its effect as a protein drug relies on the fact that cancerous lymphoblasts cannot synthesize sufficient levels of asparagine due to down-regulation of their asparagine synthetase. ${ }^{8,9}$ Therefore, contrary to normal cells, asparagine is an essential amino acid for malignant cells whose survival is exclusively dependent on the availability of extracellular asparagine from the bloodstream. Intravenously or intramuscularly administered L-ASNase depletes the available free asparagine from the extracellular fluid, ${ }^{10}$ resulting in protein and nucleic acid synthesis inhibition, which ultimately leads to cell apoptosis. ${ }^{11}$

Bacterial L-ASNase is the only nonhuman enzyme that has been approved by the American Food and Drug Administration (FDA) for treatment of ALL. ${ }^{12}$ The isoforms that are currently used are recombinantly produced proteins derived from Escherichia coli and Erwinia chrysanthemi L-ASNases. Many severe toxic side effects have been attributed to the bacterial origins of these L-ASNases, the most important one being immunogenicity; others include hepatic dysfunctions, pancreatitis, central nervous system abnormalities, anorexia, hyperglycemia, thrombosis, and quite frequently, lethal hypersensitivity reactions. ${ }^{13-15}$ Certain side effects are thought to be caused by the intrinsic glutaminase activity of bacterial LASNases, influencing both the glutamine and glutamic acid levels. ${ }^{16}$ Glutamine is the major transport form of amino nitrogen in blood, and glutamic acid has a notable impact on the central nervous system, since it plays a key role as a

Received: September 6, 2013

Revised: October 17, 2013

Published: October 21, 2013 
neurotransmitter. However, the major limitation of L-ASNase used as an anticancer agent is related to the so-called "silent inactivation" of the enzyme. ${ }^{17}$ This inactivation arises from the interaction with specific antibodies which are generated upon recognition of the enzyme as antigen by the patient's immune system, and this is usually not accompanied by any clinical symptoms of hypersensitivity. ${ }^{18,19}$ This inactivation of LASNase, which manifests itself in a blood serum half-life of only about $24 \mathrm{~h}$, necessitates continuous administration and progressively higher doses of the therapeutic enzyme. ${ }^{19}$ It has also been shown recently ${ }^{20}$ that, apart from silent inactivation, two highly specific lysosomal proteases degrade L-ASNase and therefore are coresponsible for the clearance of the enzyme.

The search for biochemical strategies to increase the half-life of the enzyme has prompted considerable efforts to enhance the stability of L-ASNase, by protecting it through surface modifications and packaging into nanocapsules ${ }^{21}$ and nanospheres. ${ }^{22}$ Encapsulation potentially prevents exposure of the enzyme to the immune system. Furthermore, the enzyme would be protected from degradation by proteases resulting in extended serum half-life. A promising example for success in such efforts was the development of the FDA-approved polyethyleneglycol-modified (PEGylated) form of E. coli LASNase, which diminished the immunogenicity, and raised the in vivo half-life of the enzyme considerably. ${ }^{19,23-25}$ Another study showed that polysialylation of the enzyme ${ }^{26}$ gradually reduced the antigenicity of the enzyme depending on the degree of lysine side-chain modification by polysialic acid, whereas no immune response was elicited against the conjugated agent. The most recent advance toward improving the therapeutic potential of L-ASNase relies on the use of intact erythrocytes ${ }^{27}$ as carriers of the therapeutic enzyme. Although the first preliminary clinical results are quite promising, the whole process is rather time-consuming, complex, and expensive, requiring patient-specific strategies of personalized medicine.

Herein, we report on a novel approach for encapsulation of asparaginase using glutaminase-free Saccharomyces cerevisiae cytoplasmic L-asparaginase I (ScASNaseI) as model enzyme. We capitalize on the use of the layer-by-layer ( $\mathrm{LbL}$ ) method of microcapsule formation. ${ }^{28-32}$ This technique allows biomolecules to be efficiently adsorbed onto a colloidal core particle, which serves as template for the consecutive adsorption of several layers of oppositely charged polymers. The last step of capsule formation includes the dissolution of the template material, which ultimately gives rise to hollow capsules that contain the initially adsorbed biomolecule. The polymers used for therapeutic proteins ideally are biocompatible. Numerous examples of successful encapsulation of proteins, ${ }^{33-35}$ polymers, ${ }^{36}$ and nucleic acids ${ }^{37}$ using this technique have been reported.

In the present study, the encapsulation of L-asparaginase was performed using calcium carbonate particles as templates for protein adsorption, which subsequently were coated with cationic poly-L-arginine and anionic dextran sulfate layers. ${ }^{32}$ The capsules were then treated with EDTA, resulting in the removal of $\mathrm{CaCO}_{3}$ and formation of the final polyelectrolyte capsules. As L-asparaginase is a protein drug with considerable interest for further improvement of its use in blood cancer therapy, we aimed to investigate whether biocompatible encapsulation could be applied to the packaging of this enzyme in order to enhance its biochemical stability and ultimately prolong its ability to maintain catalytic activity in an in vivo situation. We chose as model enzyme the yeast L-asparaginase ScASNaseI, which is a glutaminase-free L-asparaginase with promising catalytic properties. In cell culture experiments, encapsulated and free enzyme displayed similar potency in inducing apoptotic cell death. Thus, our work suggests that efficient encapsulation of therapeutic proteins, in combination with successful enzyme engineering, could set the basis for novel ways for alternative treatment of blood cancers. This view is supported by recent reports on advances in encapsulation of enzymes using various types of polymers ${ }^{38,39}$ for medical applications of nanocontainers as carriers of bioactive molecules. ${ }^{40,41}$

\section{MATERIALS AND METHODS}

Materials. Ethylenediamine-tetraacetic acid disodium salt (EDTA), calcium chloride $\left(\mathrm{CaCl}_{2}\right)$, sodium carbonate $\left(\mathrm{Na}_{2} \mathrm{CO}_{3}\right)$, dextran sulfate sodium salt $\left(M_{\mathrm{w}} \sim 10 \mathrm{kDa}\right)$, poly-L-arginine hydrochloride $\left(M_{\mathrm{w}}>70 \mathrm{kDa}\right)$, yeast extract, peptone from casein, $\mathrm{NaCl}$, and Nessler's reagent were purchased from Sigma-Aldrich-Fluka (St. Louis, MO). Dialysis membranes and Coomassie Brilliant Blue (Bradford) reagent were from ROTH (Karlsruhe, Germany). Oligonucleotides were purchased from IBA GmbH (Goettingen, Germany). Restriction enzymes, T4 DNA ligase and Trypsin Ultra isolated from bovine pancreas were obtained from New England Biolabs (Ipswich, MA). Thrombin from bovine plasma was from Serva (Heidelberg, Germany). KAPA HiFi Polymerase and all PCR reagents were purchased from PeqLab (Erlangen, Germany). Gel extraction and PCR purification kit as well as nickel agarose for protein purification were purchased from Macherey Nagel (Düren, Germany). Plasmid purification kit was from Fermentas (Thermo Fisher Scientific, Germany). Genomic DNA preparation kit was obtained from Qiagen (Hilden, Germany). RPMI 1640 cell culture medium was from PAA (Cölbe, Germany) and WST-1 proliferation kit was purchased from Roche (Mannheim, Germany).

Cloning, Expression and Purification of ScASNasel, EcASNasell, and eGFP-SCASNasel Fusion Protein. The preparation of ScASNaseI, EcASNaseII, and eGFP-ScASNaseI fusion protein was done as described in the Supporting Information.

Preparation of ScASNasel-Loaded Calcium Carbonate Particles. $\mathrm{CaCO}_{3}$ microparticles were prepared by mixing equal molar amounts of $\mathrm{Na}_{2} \mathrm{CO}_{3}$ and $\mathrm{CaCl}_{2}$ under stirring at room temperature at working concentrations of $0.15 \mathrm{M}$ each dissolved in $\mathrm{ddH}_{2} \mathrm{O}$. For the loading of protein, the coprecipitation approach was followed. To obtain calcium carbonate cores loaded with ScASNaseI, we added $2 \mathrm{~mL}$ of protein solution $\left(1.5 \mathrm{mg} / \mathrm{mL}\right.$ in $50 \mathrm{mM} \mathrm{Na}_{2} \mathrm{HPO}_{4}$, $0.5 \mathrm{M} \mathrm{NaCl}, \mathrm{pH} 7.5$ ) to $2 \mathrm{~mL}$ of $\mathrm{Na}_{2} \mathrm{CO}_{3}$ prior to mixing with $2 \mathrm{~mL}$ of $\mathrm{CaCl}_{2}$. Following mixing (for $60 \mathrm{~s}$ at $1000 \mathrm{rpm}$ ) after addition of $\mathrm{CaCl}_{2}$ and the formation of $\mathrm{CaCO}_{3}$ microparticles, the enzyme was entrapped in the porous structure of the templates. Subsequently, the particles were spun down (at $400 \mathrm{~g}$ for $5 \mathrm{~min}$ ) and washed three times with $50 \mathrm{mM} \mathrm{Na}_{2} \mathrm{HPO}_{4}, 0.5 \mathrm{M} \mathrm{NaCl}, \mathrm{pH}$ 7.5. The number of formed $\mathrm{CaCO}_{3}$ particles was determined by using a hemocytometer (BrightLine).

To obtain calcium carbonate particles loaded with eGFPScASNasel, we used the same protocol as mentioned above with minor changes, that is, $1 \mathrm{~mL}(0.8 \mathrm{mg} / \mathrm{mL})$ of eGFP-labeled protein was added to $2 \mathrm{~mL}$ of $\mathrm{CaCl}_{2}$ prior to mixing with $2 \mathrm{~mL}$ of $\mathrm{Na}_{2} \mathrm{CO}_{3}$. Then the mixture was stirred for $1 \mathrm{~min}$ at $1000 \mathrm{rpm}$ after adding of $\mathrm{Na}_{2} \mathrm{CO}_{3}$.

Determination of Protein Loading Efficiency in Calcium Carbonate Particles. To evaluate the loading efficiency of ScASNaseI after the precipitation reaction, the formed $\mathrm{CaCO}_{3}$ particles were centrifuged, washed, and counted. The amount of the enzyme present in the supernatant after coprecipitation, as well as after each washing step, was determined spectrophotometrically by the dyebinding method according to Bradford ${ }^{42}$ using BSA fraction $\mathrm{V}$ as protein standard. The loading efficiency is expressed as amount of enzyme per $\mathrm{CaCO}_{3}$ particle. The encapsulation efficiency was similarly 
estimated by subtracting the loss of protein after centrifugation and washing steps from the total enzyme amount initially used for coprecipitation.

Formation of Hollow Multilayer Polyelectrolyte Microcapsules. The layer-by-layer (LbL) technique was applied in order to prepare multilayer polyelectrolyte microcapsules. Briefly, the protein-loaded $\mathrm{CaCO}_{3}$ particles were first suspended in $1 \mathrm{~mL}$ of 1 $\mathrm{mg} / \mathrm{mL}$ dextran sulfate dissolved in $0.5 \mathrm{M} \mathrm{NaCl}, \mathrm{pH} 6.5$ (adjusted with $\mathrm{HCl} / \mathrm{NaOH}$ ), and the sample was shaken at $1200 \mathrm{rpm}$ at $25^{\circ} \mathrm{C}$ for 20 $\mathrm{min}$. After the attachment of the first polyelectrolyte layer, the particles were centrifuged at $400 \mathrm{~g}$ for $5 \mathrm{~min}$, washed 3 times with washing buffer ( $\left.50 \mathrm{mM} \mathrm{Na}_{2} \mathrm{HPO}_{4}, 0.5 \mathrm{M} \mathrm{NaCl}, \mathrm{pH} 7.5\right)$, and then dispersed in a solution containing $1 \mathrm{mg} / \mathrm{mL}$ poly-L-arginine. In the present work, overall 2 or 3 polyelectrolyte bilayers were incorporated. The fractions after each washing step were collected to determine the loss of protein. To obtain hollow multilayer polyelectrolyte microcapsules loaded with functional L-asparaginase, we modified the widely used standard protocol by dissolving the template material by dialysis under mild conditions, rather than by direct addition of the calcium-chelating agent EDTA, as outlined in Scheme 1. To this end, the initial batch

Scheme 1. Schematic Illustration of the Preparation of ScASNaseI-Filled Polyelectrolyte Capsules ${ }^{a}$

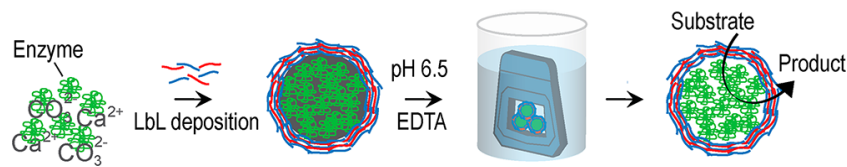

${ }^{a}$ After coating with the outermost polyelectrolyte layer (here: poly-Larginine), the suspension was subjected to overnight-dialysis yielding the final homogeneous hollow capsules containing active L-ASNase.

preparation was divided into smaller volumes which were dialyzed overnight at $4{ }^{\circ} \mathrm{C}$ (volume ratio $1: 1000$ ) against dialysis buffer (50 $\mathrm{mM} \mathrm{Na}_{2} \mathrm{HPO}_{4}, 0.5 \mathrm{M} \mathrm{NaCl}, 20 \mathrm{mM}$ EDTA, $\mathrm{pH}$ 6.5). Following this protocol, we managed to dissolve the $\mathrm{CaCO}_{3}$ cores resulting in the formation of microcapsules containing catalytically active ScASNaseI.

Zeta Potential Measurements. The zeta $(\mathrm{Z})$ potential of the microparticles was measured before adsorbing the first layer to the $\mathrm{CaCO}_{3}$ cores, and then after each polyelectrolyte adsorption step, in order to determine the surface charge. The measurements were performed on a Zetasizer Nano Series analyzer (Malvern). Samples were prepared by dispersing $50 \mu \mathrm{L}$ aliquots of coated microparticles in $1 \mathrm{~mL}$ of $\mathrm{ddH}_{2} \mathrm{O}$. Zeta potential values were determined according to the manufacturer's instructions; measurements on each sample were repeated three times.

Light Microscopy. The formation of $\mathrm{CaCO}_{3}$ particles and of the final microcapsules was followed by light microscopy. Therefore, aliquots of proper dilutions of the batch preparation were placed on a cover glass, and particles were analyzed for spherical homogeneity using an Olympus SZX12 stereo microscope with the following settings: DFPLFL 1.6X PF objective and 144× magnification using a $10 \times$ eyepiece.

Confocal Laser-Scanning Fluorescence Microscopy (CLSM). Confocal micrographs were recorded with a Leica TCS SP confocal scanning microscope (Leica, Germany) in the inverted microscope mode, using a $100 \times$ oil immersion objective with the numerical aperture of 1.4. The excitation wavelength was $488 \mathrm{~nm}$ for eGFPlabeled fusion protein.

Scanning Electron Microscopy (SEM). Scanning electron microscopy images of the capsules filled with active ScASNaseI were taken on samples prepared as follows: capsules in suspension were dropped on silica wafer and were left to dry at room temperature. The wafer was then immobilized on an aluminum stage by using an intermediate carbon layer. Finally, the sample was sputtered with gold film, and was analyzed using a Philips XL30 at $3 \mathrm{kV}$.

L-Asparaginase Activity Assay. The enzymatic activity of ScASNaseI was determined by the Nesslerization method detecting ammonia, as described elsewhere. ${ }^{43}$ Briefly, the encapsulated enzyme was incubated with the substrate L-asparagine in $50 \mathrm{mM} \mathrm{Na}_{2} \mathrm{HPO}_{4}, 0.5$ $\mathrm{M} \mathrm{NaCl}, \mathrm{pH} 7.5$, under saturation conditions ( $5 \mathrm{mM}$ asparagine) at 37 ${ }^{\circ} \mathrm{C}$ for $20 \mathrm{~min}$. In parallel, a second identical sample was incubated at $37{ }^{\circ} \mathrm{C}$ for $20 \mathrm{~min}$, in which the enzymatic reaction was quenched at time zero by adding trichloroacetic acid (TCA) to a final concentration of $10 \%$. After TCA precipitation, both samples were centrifuged at $16100 \mathrm{~g}$ for $2 \mathrm{~min}$. The supernatant was mixed with Nessler's reagent, which is a solution of potassium tetraiodomercurate that forms a yellowish complex with ammonia. The absorbance was monitored spectrophotometrically at $\sim 440 \mathrm{~nm}$ after 10 min incubation at room temperature. The concentration of ammonia produced by the enzymatic reaction was determined from a reference curve using ammonium chloride as standard. An enzymatic unit is defined as the amount of enzyme that catalyzes the conversion of $1 \mu$ mole of $\mathrm{L}$ asparagine per minute under the aforementioned conditions.

Proteolytic Resistance of Encapsulated ScASNasel. Microcapsules filled with $S c$ ASNaseI $\left(\sim 4 \times 10^{7} / \mathrm{mL}\right)$, suspended in $50 \mathrm{mM}$ $\mathrm{Na}_{2} \mathrm{HPO}_{4}, 0.5 \mathrm{M} \mathrm{NaCl}, \mathrm{pH} 7.5$, were aliquoted in $1 \mathrm{~mL}$ samples, mixed independently with either $10 \mu \mathrm{g}$ trypsin (0.02 total units) or 10 $\mu \mathrm{g}$ thrombin (10 total units) and then incubated at $37{ }^{\circ} \mathrm{C}$. Trypsin stock solution $(2 \mathrm{mg} / \mathrm{mL})$ was stored in $50 \mathrm{mM}$ Tris- $\mathrm{HCl}, 20 \mathrm{mM}$ $\mathrm{CaCl}_{2}, \mathrm{pH}$ 8.0; lyophilized thrombin was dissolved in $50 \mathrm{mM}$ Tris$\mathrm{HCl}, 140 \mathrm{mM} \mathrm{NaCl}, 2 \mathrm{mM} \mathrm{CaCl}$, pH $8.0(2 \mathrm{mg} / \mathrm{mL})$. After different periods of time, residual asparaginase activity was measured. Free enzyme, exhibiting initial volumetric activity similar to the encapsulated sample, was incubated in parallel at $37{ }^{\circ} \mathrm{C}$ using the same concentration of proteases. Its residual activity was also evaluated at different time intervals.

Thermal Stability of Free and Encapsulated ScASNasel. Irreversible thermal inactivation of free and encapsulated enzyme was followed by activity measurements. Both preparations resuspended in $50 \mathrm{mM} \mathrm{Na}_{2} \mathrm{HPO}_{4}, 0.5 \mathrm{M} \mathrm{NaCl}, \mathrm{pH} 7.5$, were incubated for $10 \mathrm{~min}$ at different temperatures covering the range $4-65^{\circ} \mathrm{C}$ and then placed on ice for an additional $10 \mathrm{~min}$ to recover. Subsequently, equal volumes of the samples were assayed for activity. Residual activity is expressed as relative (\%) activity in comparison to the initial activity $(\mathrm{U} / \mathrm{mL})$, which was equal for control and samples. The midinactivation temperature $T_{\mathrm{m}}$ is defined as the temperature at which the enzyme retains $50 \%$ of its initial activity and was calculated by plotting the relative residual activity against the temperature.

The rate of isothermal inactivation of the free and encapsulated enzyme was studied at $37{ }^{\circ} \mathrm{C}$ in $50 \mathrm{mM} \mathrm{Na} \mathrm{HPO}_{4}, 0.5 \mathrm{M} \mathrm{NaCl}, \mathrm{pH}$ 7.5 buffer. Samples with equal initial activities were incubated at $37^{\circ} \mathrm{C}$, and their residual activities were measured at defined time intervals over $30 \mathrm{~h}$. The first order inactivation rate constants $k$ were determined from the slopes of the inactivation time courses according to the equation $\ln \left(A_{t} / A_{0}\right)=-k t$, where $A_{0}$ is the initial enzymatic activity, and $A_{t}$ is the activity after time $t$. Rate constants $k$ were estimated by linear regression analysis using the Igor Pro data analysis software (Wavemetrics).

Storage Stability of Free and Encapsulated ScASNasel. Preparations of free and encapsulated $S c$ ASNaseI in $50 \mathrm{mM} \mathrm{Na}_{2} \mathrm{HPO}_{4}$, $0.5 \mathrm{M} \mathrm{NaCl}, \mathrm{pH} 7.5$, exhibiting similar initial volume activities were stored at $4{ }^{\circ} \mathrm{C}$ in the absence of protein stabilizers (such as glycerol). Residual activities of both samples were monitored every week for a total period of 3 months.

In Vitro Killing of Cancerous Lymphocytes by Encapsulated ScASNasel. To assess the effect of encapsulated ScASNaseI on cancerous lymphocytes, we performed cell culture experiments using the two leukemic cell lines SD1 and MOLT-4. Both cell lines were obtained from DSMZ (German Collection of Microorganisms and Cell Cultures, Braunschweig). SD1 cells belong to the $\mathrm{B}$ lymphoblastoid type of cells and have a doubling time of $\sim 30 \mathrm{~h}$, while MOLT-4 cells are derived from $\mathrm{T}$ leukemic cells and have a doubling time of $\sim 40 \mathrm{~h}$. The SD1 cell line was cultured at $37{ }^{\circ} \mathrm{C} / 5 \%$ $\mathrm{CO}_{2}$ in RPMI 1640 medium (PAA) with $10 \%$ FBS, while MOLT-4 cells were cultured at $37{ }^{\circ} \mathrm{C} / 5 \% \mathrm{CO}_{2}$ in RPMI 1640 with $20 \%$ FBS. Media were supplemented with a final concentration of $1 \%$ penicillin/ streptomycin. 
For the L-asparaginase treatment of these two cell lines, we used as reference enzyme EcASNaseII which is the currently approved antileukemic enzyme drug. Recombinant production and purification of the E. coli enzyme were done similar to ScASNaseI (see Supporting Information). Capsules containing either EcASNaseII or ScASNaseI were prepared as described above. Before mixing the capsules with the cells, they were made contaminant-free by exposing them to lowintensity UV-light for $10 \mathrm{~min}$, while the free enzymes were passed through a $0.2 \mu \mathrm{m}$ filter (Sartorius). Subsequently, the enzymatic activities were determined as described above, and equal volume activities of the encapsulated and the free enzyme were used to treat the leukemic cells.

For cell proliferation studies, $\sim 10^{6}$ MOLT -4 and $10^{5}$ SD1 cells in a final volume of $200 \mu \mathrm{L}$ in a 96-well plate, were mixed with five units of either encapsulated or free EcASNaseII or ScASNaseI. To test whether encapsulation of the enzyme protected it against trypsin and thrombin degradation under cell culture conditions, the same number of cells were mixed with five units of $\mathrm{L}$-asparaginase in the presence of both proteases. Trypsin was added in a final amount of $0.5 \mu \mathrm{g}$, and thrombin at $20 \mu \mathrm{g}$ per a $200 \mu \mathrm{L}$ volume, to mimic the physiological (presence of thrombin) and the pancreatitis (release of trypsin) conditions in serum. ${ }^{44,45}$ As control, cells were treated with empty capsules and proteases independently to investigate whether they affected the cells in the absence of enzyme. The cell proliferation status after $72 \mathrm{~h}$ of incubation under the aforementioned conditions was assessed using the WST-1 assay (Roche), which quantifies the activity of mitochondrial dehydrogenases, according to the manufacturer's instructions. Absorbance was measured at $450 \mathrm{~nm}$ against a background control (culture medium without cells). All treatments and measurements were done in triplicates. The proliferation state of the treated cells is expressed as relative survival (\%) against the untreated cells.

\section{RESULTS AND DISCUSSION}

Characterization of $\mathrm{CaCO}_{3}$ Particles and Polyelectrolyte Microcapsules. Enzyme-loaded microparticles formed by rapid mixing of $\mathrm{Na}_{2} \mathrm{CO}_{3}$ and $\mathrm{CaCl}_{2}$ in the presence of ScASNaseI exhibited an average size of $1-2 \mu \mathrm{m}$. We observed that microparticles of more homogeneous size and spherical morphology (Figure S5) were obtained when lower than suggested ${ }^{28,30}$ concentrations of $\mathrm{Na}_{2} \mathrm{CO}_{3}$ and $\mathrm{CaCl}_{2}$ were used. Therefore, the initial concentrations of $\mathrm{Na}_{2} \mathrm{CO}_{3}$ and $\mathrm{CaCl}_{2}$ were $0.15 \mathrm{M}$, rather than $1 \mathrm{M}$ or $0.33 \mathrm{M}$, as reported before. Additionally, we chose the coprecipitation method for protein loading, because multiple attempts to load the protein onto preformed microparticles resulted in very low loading efficiency. ${ }^{46}$ On the contrary, in the case of simultaneous mixing of enzyme with $\mathrm{Na}_{2} \mathrm{CO}_{3}$ and $\mathrm{CaCl}_{2}$ (coprecipitation method), almost the total amount of added protein was bound by the $\mathrm{CaCO}_{3}$ microparticles, such that under conditions described in Materials and Methods, $3 \mathrm{mg}$ of enzyme could be loaded with negligible loss $(\sim 0.06 \mathrm{mg})$. When trying to load higher amounts $(4 \mathrm{mg})$, we detected considerable loss of protein.

To quantify the average amount of protein bound per particle, the formed particles were counted using a hemocytometer. Under the aforementioned conditions, we found that the loaded enzyme was distributed in $\sim 10^{8}$ particles, thus, estimating that each particle contained approximately $30 \mathrm{pg}$ ScASNaseI. At this point, it is worth mentioning that ScASNaseI has a calculated isoelectric point $(\mathrm{pI})$ of $\sim 5.3$, indicating that, at the working $\mathrm{pH}$ of 7.5 , the enzyme is negatively charged, while on the other hand, $\mathrm{CaCO}_{3}$ particles are positively charged at $\mathrm{pH}$ values below 9.0. ${ }^{30}$ Therefore, one may assume that high loading efficiency can be attributed to favorable electrostatic interactions between the protein and the calcium carbonate template, in addition to the high degree of adsorption of the enzyme to interior cavity surfaces of the template during the formation of the cores. When loading the enzyme following the same procedure at $\mathrm{pH} 6$ (closer to the enzyme's pI), we observed a 5-fold higher protein loss in the coprecipitation as well as in the washing steps (Figure S6). The enzyme-loaded particles were subjected to stepwise polyelectrolyte coating, starting with dextran sulfate, followed by poly-Larginine. We chose these two polyelectrolytes because of their biocompatibility properties, envisioning future in vivo studies. During the adsorption process, the electrophoretic mobility (zeta potential) was measured after deposition of each polyelectrolyte layer (Figure S7).

Prior to LbL-coating, $\mathrm{CaCO}_{3}$ cores exhibited a positive zeta potential, and therefore, coating was started with dextran sulfate (negatively charged) as the inner layer. After coating with two bilayers, hollow protein-containing capsules were obtained by dialyzing the material against $50 \mathrm{mM} \mathrm{Na}_{2} \mathrm{HPO}_{4}, 0.5 \mathrm{M} \mathrm{NaCl}$, 20 mM EDTA, pH 6.5 (volume ratio 1:1000). We established this modified protocol for dissolution of the $\mathrm{CaCO}_{3}$ template as we observed an inactivating effect of the chelating agent on ScASNaseI when using EDTA at concentrations $\sim 0.1 \mathrm{M}$ or higher. Therefore, the standard method of immersing the coated particles in 0.1 M EDTA was not ideal for this particular enzyme. By testing the inhibitory effect on enzymatic activity using free enzyme (Figure S8), we found that concentrations up to $20 \mathrm{mM}$ EDTA were tolerated by this enzyme. Thus, by dialyzing the coated particles against buffer containing $20 \mathrm{mM}$ EDTA, we managed to dissolve the core material thereby preserving the activity of the enzyme. This is of great importance for encapsulation of therapeutic proteins; most likely, this protocol must be adapted to milder conditions of template removal if less robust proteins of human origin are to be packaged in microcapsules (unpublished data). Moreover, we point out that the dialysis method for template dissolution can be used equally efficiently when more than two bilayers of polyelectrolytes are used for coating. In this work, we focused on the characterization of capsules with two bilayers, instead of three or more, since we observed a delay of reaching the saturation point of the enzymatic reaction in the case of more bilayers, possibly due to rate-limiting substrate or product diffusion through the polymer shell (Figure S9). Figure 1 shows two confocal as well as two scanning electron microscopy images of the final hollow capsules (with two bilayers) loaded with active ScASNaseI or eGFP-ScASNaseI (green fluorescence). The average diameter of the generated capsules was $\sim 1-2 \mu \mathrm{m}$.

The total number of protein-loaded capsules was determined by again using a hemocytometer; this number was found to be $\sim 8 \times 10^{7}$, which is roughly equal to the initial number of particles. However, while it is possible to determine the amount of enzyme loaded on $\mathrm{CaCO}_{3}$ and calculate the approximate amount of enzyme per particle, such quantitative protein data are more difficult to obtain for the capsules. The reason is that when using poly amino acids, such as poly-L-arginine, for capsule formation, these polymers interfere with protein determination assays. ${ }^{32}$ Moreover, it has been shown ${ }^{32}$ that during the last step of $\mathrm{CaCO}_{3}$ core removal, a significant fraction of either adsorbed or coprecipitated protein is released. This release seems to directly correlate with the size of the entrapped macromolecule, while physicochemical properties and the number of bilayers also are important parameters. ${ }^{47}$ Accurate measurements of protein entrapped in the final 

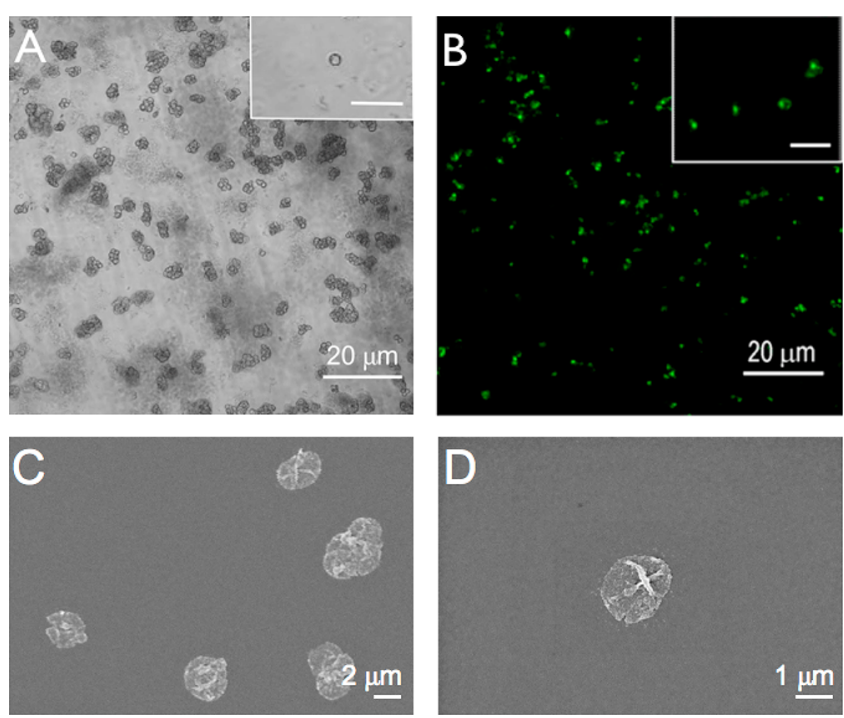

Figure 1. (A) Shown are two-bilayer-microcapsules loaded with ScASNaseI, after EDTA dissolution by dialysis. Images were taken using a confocal laser scanning microscope as described in Materials and Methods. The inset shows a capsule zoomed from the main image (scale bar corresponds to $5 \mu \mathrm{m}$ ). (B) Confocal fluorescence image of microcapsules loaded with eGFP-ScASNaseI fusion protein. Inset is the zoomed area of the main image (scale bar corresponds to $3 \mu \mathrm{m}$ ). (C, D) SEM images of polyelectrolyte microcapsules after removal of the $\mathrm{CaCO}_{3}$ template by dialysis.

capsules may necessitate the use of radiolabeled proteins, but this method is not applicable in all cases. In future work, it will be of general interest to establish a more direct and accurate, radio-label-free method for the determination of protein load in microcapsules. As a compromise in the present study, we compare volume activities of the free and encapsulated enzyme rather than specific activities, because the amount of unlabeled enzyme per capsule cannot be determined.

Resistance of Encapsulated ScASNasel to Proteolysis. A critical complication occurring during treatment of ALL with bacterial L-ASNase is acute pancreatitis, ${ }^{48}$ causing the release of the protease trypsin in the patient's blood serum and inactivation of the administered enzyme. In addition, it has been shown recently, that a dyad of lysosomal proteases degrades specifically E. coli L-ASNase. Therefore, it is of great interest to assess the resistance of encapsulated enzyme to proteolytic degradation. Besides trypsin, we tested the serine protease thrombin which has a key role in blood coagulation reactions. ${ }^{49}$ Equal amounts of both proteases, yet with different specific and total activities (see Materials), were mixed with free and encapsulated ScASNaseI exhibiting similar volume activities. Samples were incubated at $37{ }^{\circ} \mathrm{C}$, and residual activity was measured at successive time points (Figures 2 and 3) for up to $7 \mathrm{~h}$. Our results show that encapsulated L-ASNase is considerably more resistant to trypsin and thrombin degradation. The free enzyme was very sensitive to trypsin treatment, as evidenced by the fact that, after $1 \mathrm{~h}$ incubation, its remaining activity was below 5\%. In contrast, encapsulated LASNase resisted significantly better to trypsin exposure, maintaining up to $\sim 20 \%$ activity even after $7 \mathrm{~h}$.

In contrast to trypsin, thrombin was better tolerated by both free and encapsulated ASNase. Analysis of the primary structure provides a potential explanation for this higher resistance against thrombin. ScASNaseI amino acid sequence analysis

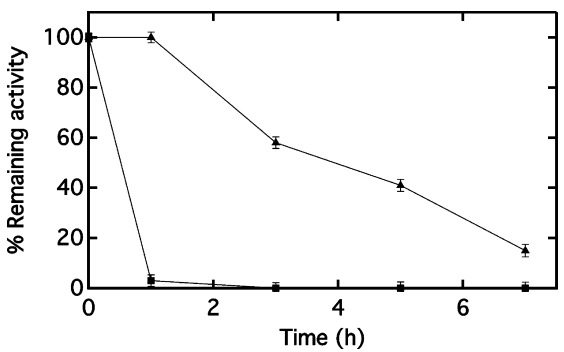

Figure 2. Residual activities of free ( $\boldsymbol{\square}$ ) and encapsulated ( $\boldsymbol{\Delta}$ ) ScASNaseI incubated with trypsin at $37^{\circ} \mathrm{C}$. Activities were measured every $2 \mathrm{~h}$ upon incubation with the protease. Results are means $\pm \mathrm{SD}$ of two independent experiments.

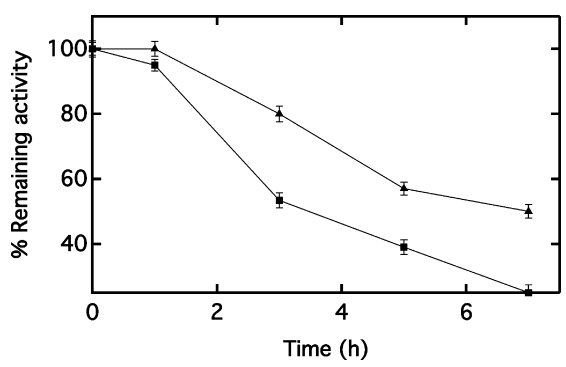

Figure 3. Residual activities of free ( $\boldsymbol{\square})$ and encapsulated ( $\boldsymbol{\Delta}$ ) ScASNaseI incubated with thrombin at $37{ }^{\circ} \mathrm{C}$. Similarly to trypsin treatment, activities were measured every $2 \mathrm{~h}$ upon incubation with the protease. Results are means \pm SD of two independent experiments.

(using Peptide Cutter, Expasy) revealed 31 possible recognition sites for trypsin, but only one for thrombin. Taking into account the molecular sizes of proteins such as trypsin (native $\mathrm{MW} \sim 23.6 \mathrm{kDa})$ and thrombin $(\sim 36 \mathrm{kDa})$, it can be assumed that they should be unable to diffuse into the capsules, though under specific temperature and ionic strength conditions, this may happen to some extent.

Additionally, one may assume that the encapsulated enzyme is mostly localized close to the inner surface due to favorable electrostatic interactions, rather than being homogeneously distributed in the capsule's volume; in that way, the interaction with proteases would be facilitated. Indeed, during $\mathrm{LbL}$ formation of the polyelectrolyte shell around the rough calcium carbonate surface, a polyelectrolyte complex can be formed inside the porous $\mathrm{CaCO}_{3}$. This might induce binding of the protein to such a complex after core decomposition. ${ }^{30}$

Thermal and Storage Stability of Free and Encapsulated ScASNasel. Aiming at further evaluation of the structural stability of the encapsulated L-ASNase, we performed irreversible thermal inactivation experiments using the free enzyme as reference. The two enzyme preparations (free and encapsulated) were incubated at different temperatures and were then assayed for residual activity (Figure 4). The corresponding $T_{\mathrm{m}}$ values are summarized in Table 1 . We noted that the free enzyme showed a relatively high $T_{\mathrm{m}}(51.6$ ${ }^{\circ} \mathrm{C}$ ), considering its origin from yeast which grows at $30{ }^{\circ} \mathrm{C}$. A potential explanation derives from the fact that this enzyme contains 10 cysteines, which might form disulfide bonds. It is known that disulfide bonds usually stabilize the overall protein structure making it more rigid and resistant against harsh conditions such as high temperatures. ${ }^{50}$ Yet, encapsulation of this enzyme enhanced the thermostability of ScASNaseI slightly. Our observations on thermostability of L-asparaginase encapsulated by using biocompatible material and reaction 


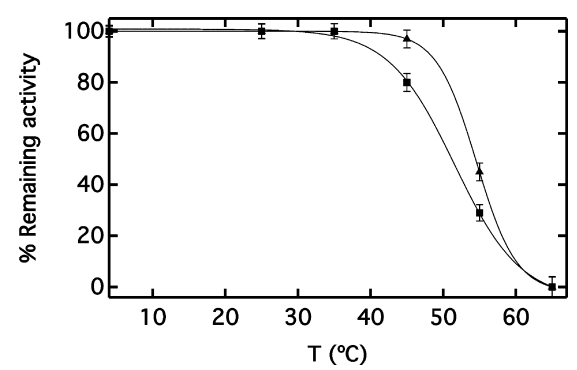

Figure 4. Irreversible thermal inactivation of free (ם) and encapsulated ( $\mathbf{\Delta})$ L-ASNase. Residual activities were measured after heat treatment at different temperatures for $10 \mathrm{~min}$. $T_{\mathrm{m}}$ values were calculated by nonlinear regression to a sigmoid function using Igor Pro (Wavemetrics) software. Results are means \pm SD of two independent experiments.

Table 1. Mid-Inactivation Temperatures and Inactivation Rate Constants \pm SD for Free and Encapsulated ScASNaseI

\begin{tabular}{lcc} 
& $T_{\mathrm{m}}\left({ }^{\circ} \mathrm{C}\right)$ & $k_{\text {in }}\left(\times 10^{-3} \mathrm{~h}^{-1}\right)$ \\
free enzyme & $51.6 \pm 0.88$ & $120 \pm 4.72$ \\
encapsulated enzyme & $54.6 \pm 0.47$ & $10 \pm 1.2$ \\
\hline
\end{tabular}

conditions, as compared to stability of the free enzyme, are in good qualitative agreement with an early report on enzyme encapsulation. ${ }^{51}$ In that work, $\alpha$-chymotrypsin was used as a model enzyme for entrapment in hollow microcapsules consisting of four double-layers of sodium poly(styrenesulfonate) (PSS) and poly(allylamine hydrochloride)(PAH) assembled on commercially available micrometer-sized melamine formaldehyde particles, and stability was measured in the temperature range from 20 to $48{ }^{\circ} \mathrm{C}$.

The time course of isothermal inactivation of the two enzyme preparations was evaluated at the physiologically relevant temperature of $37{ }^{\circ} \mathrm{C}$. Kinetic analysis yielded linear plots (Figure 5) from which the first order inactivation rate

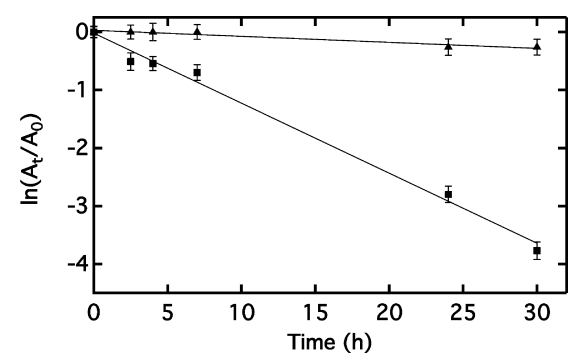

Figure 5. Plot of isothermal inactivation kinetics for free $(\boldsymbol{\square})$ and encapsulated $(\mathbf{\Delta})$ enzyme. The enzyme preparations were incubated at $37^{\circ} \mathrm{C}$, and their residual activities were measured for a period of 30 h. First order inactivation rate constants $k_{\text {in }}$ were calculated by linear regression using the Igor Pro (Wavemetrics) software. The experiment was performed twice.

constants were calculated according to eq 1 of ref 52 . We found a considerably lower inactivation rate constant (12-fold lower) for the encapsulated enzyme in comparison to the free enzyme (Table 1). We hypothesize that the microenvironment which is formed upon encapsulation protects the enzyme from different chemical and physical factors that could affect protein folding and catalytic activity. As it is generally believed that enhanced protein thermal stability is predominantly dependent on an increased number of hydrogen bonds and salt links, as well as better van der Waals' packing ${ }^{53,54}$ in the capsules' microenvironment, the latter two factors might explain the improved thermal stability of encapsulated L-ASNase at $37^{\circ} \mathrm{C}$.

The storage stability of the encapsulated enzyme was also significantly improved in comparison to the free species. As shown in Figure 6, after storing the encapsulated L-asparaginase

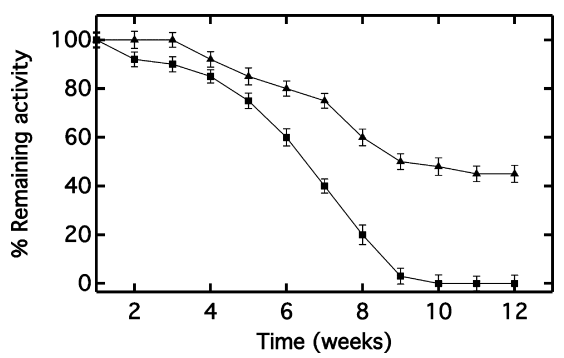

Figure 6. Plot of the storage stability for free $(\boldsymbol{\square})$ and encapsulated (A) L-ASNase. Samples were incubated at $4{ }^{\circ} \mathrm{C}$ in the absence of stabilizers. Their residual activities were measured for a total period of 3 months. The results are means \pm SD of independent measurements on three samples from the same capsule preparation.

for over 3 months at $4{ }^{\circ} \mathrm{C}$, the enzyme kept about $50 \%$ of its initial activity. In contrast, the free enzyme showed total inactivation after 2 months when stored at the same temperature. As microcapsules consist of ionic polymers such as hydrophilic polyelectrolytes (dextran sulfate and poly-Larginine in the present case), our findings are supported by previous work, ${ }^{55}$ which showed that hydrophilic polymers have a particular hydration effect on proteins similar to polyhydric alcohols (polyethylene-glycol, lactitol, sucrose) which also enhance their stability. ${ }^{49}$ Furthermore, it was shown that mixing of an enzyme with soluble linear-chain high molecular weight polymers can promote its stability, suggesting that the interaction between polymers and enzyme molecules forms a network which imposes a mechanical restriction on the protein unfolding process. ${ }^{56}$ Thus, we believe that increased storage stability of encapsulated L-ASNase can be attributed to favorable electrostatic interactions between the enzyme and the polymers.

Treatment of Leukemic Cells Using Free and Encapsulated ScASNasel. Encapsulated and free ScASNaseI were used to treat two different leukemic cell lines in order to evaluate the efficacy of both enzyme preparations on these cells. Free and encapsulated EcASNaseII were included in this series of experiments for comparative purposes, because this enzyme has been used for many decades for the treatment of ALL. In all cases, five units of each enzyme preparation (either encapsulated or free) were added once to the cells which were incubated for $72 \mathrm{~h}$. Subsequently, the proliferation state of the cells was evaluated based on the WST-1 assay.

The results of the different treatments of the two cell lines are presented in Figures 7 and 8. Figure 7 shows the relative survival of the cells which were exposed to different preparations of ScASNaseI. These data suggest that free proteases and empty capsules had no negative impact on the cells, and therefore cell death can be attributed solely to the effect of the L-ASNases. This effect on leukemic cells is due to the depletion of the available levels of L-Asn in the medium, since lack of L-Asn causes protein synthesis arrest in the cancerous cells which ultimately undergo apoptosis and cell death. $^{11}$ Figure 7 shows that the use of either free or 


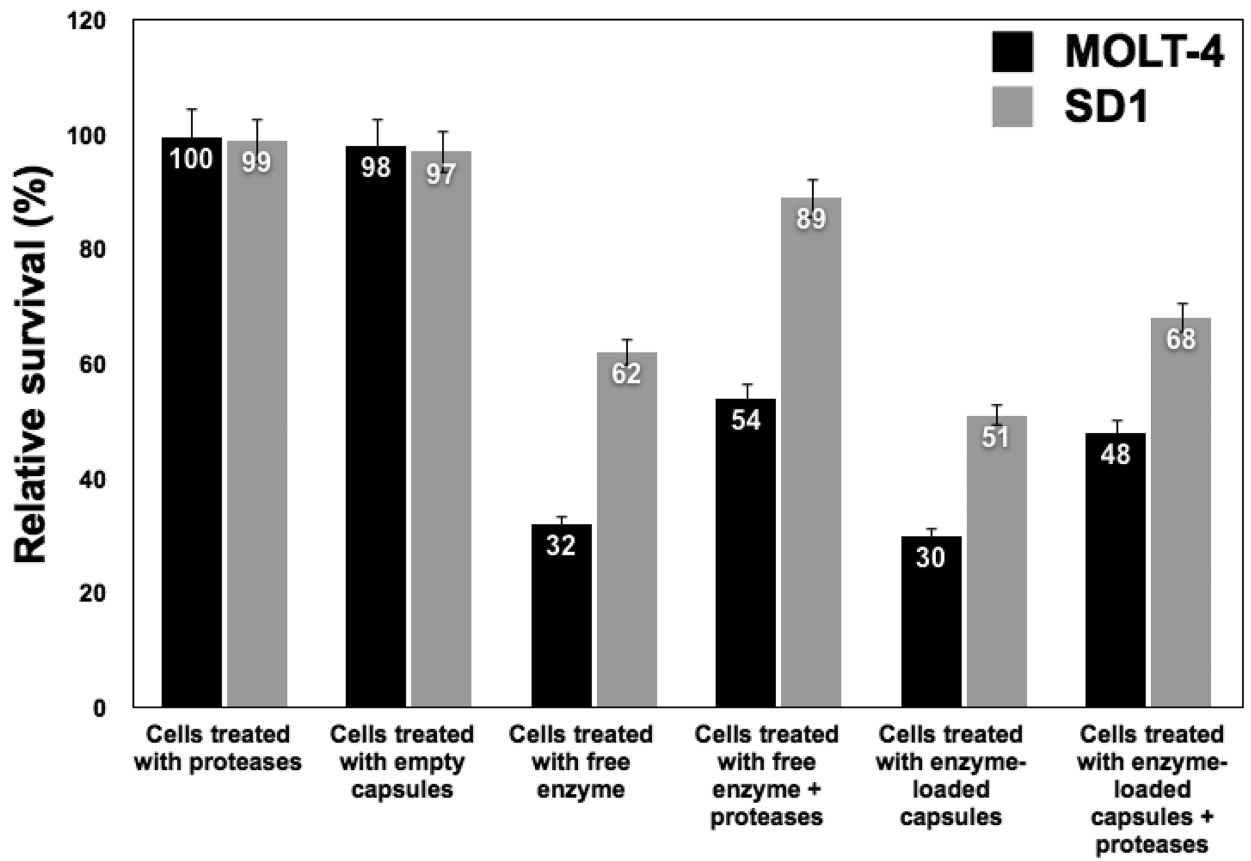

Figure 7. Viability of MOLT-4 and SD1 leukemic cells treated with ScASNaseI preparations. The proliferation state of the cells is expressed as relative survival (\%) against the control (untreated cells). Data are shown as means \pm SD of triplicate measurements.

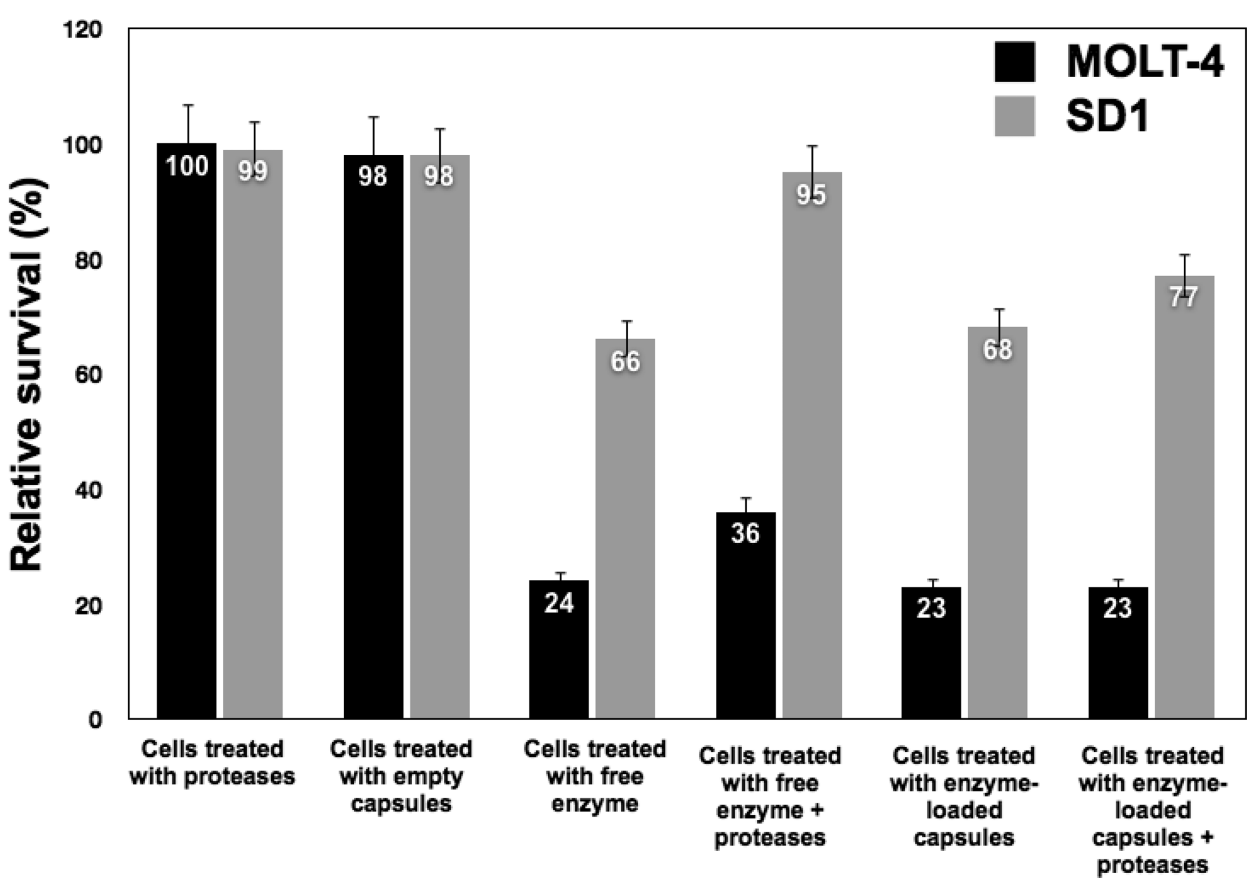

Figure 8. Viability of MOLT-4 and SD1 cells treated with EcASNaseII, expressed as relative survival (\%) against the control (untreated cells). Data are means $\pm \mathrm{SD}$ of triplicate measurements.

encapsulated ScASNaseI inhibited the MOLT-4 and SD1 proliferation after $72 \mathrm{~h}$ of treatment to a relatively similar extent. However, when the cells were incubated with free enzyme in the presence of trypsin and thrombin, the proliferation inhibition was less pronounced, indicating inactivation of ScASNaseI by the proteases. In contrast, when the cells were treated with encapsulated ScASNaseI and proteases, the proliferation of SD1 cells was inhibited similarly to the treatment with free enzyme in the absence of proteases, while MOLT-4 cells were less affected by L-asparaginase treatment. These findings on protease effects are in line with our biochemical data which implied that encapsulation of ScASNaseI significantly elevated its proteolytic resistance as compared to the free enzyme. Light microscopic images of the untreated cells and cells treated with ScASNaseI-loaded capsules are shown in the Supporting Information (Figure S10). Similar results were obtained when both leukemic cell lines were incubated with free or encapsulated EcASNaseII (Figure 8). We observed that SD1 cells were similarly affected by free ScASNaseI and EcASNaseII. In contrast, the proliferation of MOLT-4 cells was influenced more by EcASNaseII than by ScASNaseI. Encapsulation of the bacterial 
enzyme was also proven to be beneficial for its resistance against proteolysis, as evidenced by the lower relative survival resulting from the treatment with capsules in the presence of proteases as compared to the free enzyme in the presence of proteases. Images of untreated cells and of cells treated with EcASNaseII-loaded capsules, are shown in the Supporting Information (Figure S11).

Taken together, our data suggest that encapsulation of LASNases, using biocompatible polyelectrolytes, improves the biochemical stability of the enzymes and protects them against physiologically occurring proteases. We show that this protection holds for both ScASNaseI and EcASNaseII which have distinct catalytic properties $\left(k_{\text {cat }} / K_{\mathrm{M}} 5 \times 10^{4} \mathrm{M}^{-1} \mathrm{~s}^{-1}\right.$ for ScASNaseI, and $1.5 \times 10^{6} \mathrm{M}^{-1} \mathrm{~s}^{-1}$ for EcASNaseII). These findings may form the basis for an improved L-asparaginasedependent antileukemic therapy, though in vitro analyses will have to be complemented by pharmacodynamic and pharmacokinetic studies.

\section{CONCLUSION}

Recent advances in cellular drug delivery have relied on the use of polyelectrolyte microcapsules as carriers for various types of drugs, including proteins. ${ }^{57,58}$ Of great importance is the maintenance of the functionality of the loaded drug during the preparation of the capsules; this is particularly true for enzymes whose activity can be strongly affected by different materials, or by reaction conditions required for capsule fabrication. In the present work, we have highlighted the importance of removing the $\mathrm{CaCO}_{3}$ template under mild conditions of dialysis to preserve catalytic activity of the therapeutic enzyme Lasparaginase (L-ASNase) which is an approved drug for the treatment of leukemia. We focused on the up to now poorly characterized yeast asparaginase, ScASNaseI, which is a glutaminase-free enzyme exhibiting catalytic properties on asparagine that are similar to those of the currently approved E. coli protein. Therefore, this enzyme of eukaryotic origin could form the basis for the development of an improved anticancer drug showing less side effects than the bacterial enzyme

To develop a potential strategy for the amelioration of LASNase's half-life in the blood, we packaged the enzyme in microcapsules fabricated by a variable number of layers of biocompatible polymers. In this way, full catalytic activity was maintained, biochemical stability of the enzyme was enhanced, and it can be expected that the encapsulated enzyme will be protected from inactivation by proteases not only in vitro, as demonstrated in this work, but also in an in vivo situation, thus, improving the enzyme's half-life in the blood. Therefore, encapsulation appears as a promising avenue to bypass numerous problems associated with protease degradation of therapeutic peptides and proteins. Moreover, when residing inside capsules, the enzyme's epitopes would be shielded, preventing direct recognition by the immune system. ${ }^{40,41}$ However, the question of whether the capsules themselves could be immunogenic remains to be addressed. ${ }^{59}$ We are presently probing the general applicability of our experimental strategy to more sensitive biomacromolecules such as various enzymes of human origin. Notably, we embarked on encapsulation of a human L-asparaginase that we recently characterized structurally and functionally ${ }^{60}$ and that could replace enzymes of nonhuman origin.

\section{ASSOCIATED CONTENT}

\section{Supporting Information}

Enzyme preparations are described in detail, and cell culture images and complementary results are given. This material is available free of charge via the Internet at http://pubs.acs.org.

\section{AUTHOR INFORMATION}

\section{Corresponding Author}

*Fax: +49 551 2011074. E-mail: mkonrad@gwdg.de.

\section{Notes}

The authors declare no competing financial interest.

\section{ACKNOWLEDGMENTS}

This work was supported by the Max Planck Society, and by an Alexander von Humboldt fellowship to A.M.Y. We thank members of the Laboratory of Cellular Dynamics (Head: T. Jovin) for offering us the use of their Zetasizer Nano Series analyzer, as well as the Department of Cellular Biochemistry (Head: R. Lührmann) for giving us free access to their Confocal Laser-Scanning Microscope.

\section{REFERENCES}

(1) Asselin, B. L.; Ryan, D.; Frantz, C. N.; Bernal, S. D.; Leavitt, P.; Sallan, S. E.; Cohen, H. Cancer Res. 1989, 49, 4363-4368.

(2) Silverman, L. B.; Gelber, R. D.; Dalton, V. K. Blood 2001, 97, 1211-1218.

(3) Pui, C. H.; Sandlund, J. T.; Pei, D. Blood 2004, 104, 2690-2696.

(4) Jaffe, N.; Traggis, D.; Das, L.; Kim, B. S.; Hann, H. W.; Moloney, W. C.; Dohlwitz, A. Pediatrics 1972, 49, 590-595.

(5) Sallan, S. E.; Hitchcock-Bryan, S.; Gelber, R.; Cassady, J. R.; Frei, E., III; Nathan, D. G. Cancer Res. 1983, 43, 5601-5607.

(6) Tallal, L.; Tan, C.; Oettgen, H.; Wollner, N.; McCarthy, M.; Helson, L.; Burchenal, J.; Karnofsky, D.; Murphy, M. L. Cancer 1970, $25,306-320$.

(7) Ertel, I. J.; Nesbit, M. E.; Hammond, D.; Weiner, J.; Sather, H. Cancer Res. 1979, 39, 3893-3896.

(8) Capizzi, R. L.; Bertino, J. R.; Skeel, R. T.; Creasey, W. A.; Zanes, R.; Olayon, C.; Peterson, R. G.; Handschumacher, R. E. Ann. Intern. Med. 1971, 74, 893-901.

(9) Haskell, C. M.; Canellos, G. P. Biochem. Pharmacol. 1969, 18 $2578-2580$.

(10) Capizzi, R. L.; Bertino, J. R.; Skeel, R. T.; Creasey, W. A.; Zanes, R.; Olayon, C. Ann. Intern. Med. 1971, 74, 893-901.

(11) Holleman, A.; den Boer, M. L.; Kazemier, K. M.; Janka-Schaub, G. E.; Pieters, R. Blood 2003, 102, 4541-4546.

(12) Cantor, J. R.; Yoo, T. H.; Dixit, A.; Iverson, B. L.; Forsthuber, T. G.; George, Georgiou. Proc. Natl. Acad. Sci. U.S.A. 2011, 108, 12721277.

(13) Larson, R. A.; Fretzin, M. H.; Dodge, R. K.; Schiffer, C. A. Leukemia 1998, 12, 660-665.

(14) Whitecar, J. P., Jr; Bodey, G. P.; Harris, J. E.; Freireich, E. J. N. Engl. J. Med. 1972, 282, 732-734.

(15) Zubrod, C. G. Pediatrics 1970, 45, 555-559.

(16) Derst, C.; Henseling, J.; Röhm, K. H. Protein Sci. 2000, 9, 2009_ 2017.

(17) Szewczyk, B. L.; Andrzejewski, W.; Mlynarski, W.; Danska, K. R.; Witas, H.; Bodalski, J. Leuk. Lymphoma 2007, 48, 931-936.

(18) Mueller, H. J.; Boos, J. Crit. Rev. Oncol. Hematol. 1998, 28, 97113.

(19) Asselin, B. L.; Whitin, J. C.; Coppola, D. J.; Rupp, I. P.; Sallan, S. E.; Cohen, H. J. J. Clin. Oncol. 1993, 11, 1780-1786.

(20) Patel, N.; Krishnan, S.; Offman, M. N.; Krol, M.; Moss, C. X.; Leighton, C.; van Delft, F. W.; Holland, M.; Liu, J. Z.; Alexander, S.; Dempsey, C.; Ariffin, H.; Essink, M.; Eden, T. O. B.; Watts, C.; Bates, P. A.; Saha, V. J. Clin. Invest. 2009, 119, 1964-1973. 
(21) Baran, E. T.; Ozer, N.; Hasirci, V. J. Mater. Sci.: Mater. Med. 2002, 13, 1113-1121.

(22) Wolf, M.; Wirth, M.; Pittner, F.; Gabor, F. Int. J. Pharm. 2003, 256, 141-152.

(23) Rizzari, C.; Citterio, M.; Zucchetti, M.; Conter, V.; Chiesa, R.; Colombini, A.; Malguzzi, S.; Silvestri, D.; D’Incalci, M. Haematologica 2006, 91, 24-31.

(24) Cao, S. G.; Zhao, Q. Y.; Ding, Z. T.; MaL, Y. T.; Wang, J. H. Ann. N.Y. Acad. Sci. 1990, 613, 460-467.

(25) Kawashima, K.; Takeshima, H.; Higashi, Y.; Hamaguchi, M.;

Sugie, H.; Imamura, I. Leuk. Res. 1991, 15, 525-30.

(26) Fernandes, A. I.; Gregoriadis, G. Int. J. Pharm. 2001, 217, 215224.

(27) Kwon, Y. M.; Chung, H. S.; Moon, C.; Yockman, J.; Park, Y. J.; Gitlin, S. D.; David, A. E.; Yang, V. C. J. Controlled Release 2009, 139, 182-189.

(28) Volodkin, D. V.; Petrov, A. I.; Prevot, M.; Sukhorukov, G. B. Langmuir 2004, 20, 3398-3406.

(29) Sukhorukov, G. B.; Volodkin, D. V.; Gunther, A. M.; Petrov, A. I.; Shenoya, D. B.; Mohwald, H. J. Mater. Chem. 2004, 14, 2073-2081.

(30) Volodkin, D. V.; Larionova, N. I.; Sukhorukov, G. B. Biomacromolecules 2004, 5, 1962-1972.

(31) De Cock, L. J.; De Koker, S.; De Geest, B. G.; Grooten, J.; Vervaet, C.; Remon, J. P.; Sukhorukov, G. B.; Antipina, M. N. Angew. Chem., Int. Ed. 2010, 49, 6954-6973.

(32) De Temmerman, M. L.; Demeester, J.; De Vos, F.; De Smedt, S. C. Biomacromolecules 2011, 12, 1283-1289.

(33) Caruso, F.; Trau, D.; Mohwald, H.; Renneberg, R. Langmuir 2000, 16, 1485-1488.

(34) Gao, C. Y.; Liu, X. Y.; Shen, J. C.; Möhwald, H. Chem. Commun. (Cambridge, U.K.) 2002, 17, 1928-1929.

(35) Yashchenok, A. M.; Delcea, M.; Videnova, K.; Jares-Erijman, E. A.; Jovin, T. M.; Konrad, M.; Möhwald, H.; Skirtach, A. G. Angew. Chem., Int. Ed. 2010, 49, 8116-8120.

(36) Radtchenko, I. L.; Sukhorukov, G. B.; Möhwald, H. Colloids Surf., A 2002, 202, 127-133.

(37) Zelikin, A. N.; Becker, A. L.; Johnston, A. P. R.; Wark, K. L.; Turatti, F.; Caruso, F. ACS Nano 2007, 1, 63-69.

(38) Tanner, P.; Onaca, O.; Balasubramanian, V.; Meier, W.; Palivan,

C. G. Chem.-Eur. J. 2011, 17, 4552-4560.

(39) Ariga, K.; Ji, Q.; Mori, T.; Naito, M.; Yamauchi, Y.; Abe, H.; Hill, J. P. Chem. Soc. Rev. 2013, 42, 6322-6345.

(40) Sakr, O. S.; Borchard, G. Biomacromolecules 2013, 14, 21172135.

(41) Najer, A.; Wu, D.; Vasquez, D.; Palivan, C. G.; Meier, W. Nanomedicine (London, U.K.) 2013, 8, 425-447.

(42) Bradford, M. M. Anal. Biochem. 1976, 72, 248-254.

(43) Ho, P. P.; Milikin, E. B.; Bobbitt, J. L. J. Biol. Chem. 1970, 245, $3708-3715$.

(44) Artigas, J. M.; Garcia, M. E.; Faure, M. R.; Gimeno, A. M. Postgrad. Med. J. 1981, 57, 219-222.

(45) Putnam, F. W. The Plasma Proteins; Academic Press: IN, 1984.

(46) Petrov, A. I.; Volodkin, D. V.; Sukhorukov, G. B. Biotechnol. Prog. 2005, 21, 918-925.

(47) She, Z.; Antipina, M. N.; Li, J.; Sukhorukov, G. B. Biomacromolecules 2010, 11, 1241-1247.

(48) Derwich, K.; Stencel, D.; Warzywoda, M.; Leda, M. Pract. Oncol. Radiother. 1999, 4, 15-22.

(49) Tanaka, K. A.; Key, N. S.; Levy, J. H. Anesth. Analg. 2009, 108, $1433-1446$.

(50) Vogt, G.; Woell, S.; Argos, P. J. Mol. Biol. 1997, 269, 631-643.

(51) Tiourina, O. P.; Antipov, A. A.; Sukhorukov, G. B.; Larionova,

N. I.; Lvov, Y.; Möhwald, H. Macromol. Biosci. 2001, 1, 209-214.

(52) Fachin, D.; Smout, C.; Verlent, I.; Nguyen, B. L.; Van Loey, A. M.; Hendrickx, M. E. J. Agric. Food Chem. 2004, 52, 2697-2703.

(53) Querol, E.; Perez-Pons, J. A.; Mozo-Villarias, A. Protein Eng., Des. Sel. 1996, 9, 265-271.

(54) Vogt, G.; Argos, P. Fold. Des. 1997, 2, 40-46.

(55) Schmid, R. D. Adv. Biochem. Eng. 1979, 12, 42-118.
(56) Gianfreda, L.; Modafferi, M.; Greco, G., Jr. Enzyme Microb. Technol. 1985, 7, 78-82.

(57) Vergaro, V.; Scarlino, F.; Bellomo, C.; Rinaldi, R.; Vergara, D.; Maffia, M.; Baldassarre, F.; Giannelli, G.; Zhang, X.; Lvov, Y. M.; Leporatti, S. Adv. Drug Delivery Rev. 2011, 63, 847-864.

(58) Anandhakumar, S.; Nagaraja, V.; Raichur, A. M. Colloids Surf., B 2010, 78, 266-274.

(59) De Temmerman, M. L.; Rejman, J.; Vandenbroucke, R. E.; De Koker, S.; Libert, C.; Grooten, J.; Demeester, J.; Gander, B.; De Smedt, S. C. J. Controlled Release 2012, 158, 233-239.

(60) Su, Y.; Karamitros, C. S.; Nomme, J.; McSorley, T.; Konrad, M.; Lavie, A. Chem. Biol. 2013, 20, 533-540. 